\title{
Article
}

\section{Graphene/AlGaN/GaN RF Switch}

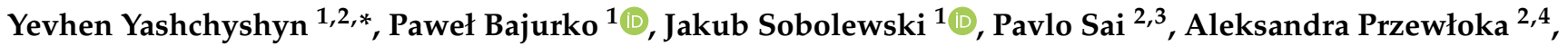 \\ Aleksandra Krajewska ${ }^{2}{ }^{-}$, Paweł Prystawko ${ }^{5}{ }^{(}$, Maksym Dub ${ }^{2,3}$, Wojciech Knap ${ }^{2,6}$, Sergey Rumyantsev ${ }^{2}(\mathbb{D}$ \\ and Grzegorz Cywiński ${ }^{2}$ (D)
}

1 Institute of Radioelectronics and Multimedia Technology, Warsaw University of Technology, 00-665 Warsaw, Poland; P.Bajurko@ire.pw.edu.pl (P.B.); J.Sobolewski@ire.pw.edu.pl (J.S.)

2 CENTERA Laboratories, Institute of High Pressure Physics PAS, 01-142 Warsaw, Poland; psai@mail.unipress.waw.pl (P.S.); aprzewloka@unipress.waw.pl (A.P.); aleksandrababis@gmail.com (A.K.); maksimdub19f94@gmail.com (M.D.); knap.wojciech@gmail.com (W.K.); roumis4@gmail.com (S.R.); gc@unipress.waw.pl (G.C.)

3 V. E. Lashkaryov Institute of Semiconductor Physics, National Academy of Sciences of Ukraine, 03680 Kyiv, Ukraine

4 Institute of Optoelectronics, Military University of Technology, 00-908 Warsaw, Poland

5 Institute of High Pressure Physics PAS, 01-142 Warsaw, Poland; pawel.prystawko@unipress.waw.pl

6 Laboratoire Charles Coulomb, UMR 5221 CNRS-University of Montpellier, 34950 Montpellier, France

* Correspondence: Y.Yashchyshyn@ire.pw.edu.pl

check for updates

Citation: Yashchyshyn, Y.; Bajurko, P.; Sobolewski, J.; Sai, P.; Przewłoka, A.; Krajewska, A.; Prystawko, P.; Dub, M.; Knap, W.; Rumyantsev, S.; et al. Graphene/AlGaN/GaN RF Switch. Micromachines 2021, 12, 1343.

https://doi.org/10.3390/mi12111343

Academic Editor: Jianping Chen

Received: 16 September 2021

Accepted: 19 October 2021

Published: 31 October 2021

Publisher's Note: MDPI stays neutral with regard to jurisdictional claims in published maps and institutional affiliations.

Copyright: (c) 2021 by the authors. Licensee MDPI, Basel, Switzerland. This article is an open access article distributed under the terms and conditions of the Creative Commons Attribution (CC BY) license (https:/ / creativecommons.org/licenses/by/ $4.0 /)$.

\begin{abstract}
RF switches, which use a combination of graphene and two-dimensional high-density electron gas (2DEG) in the AlGaN/GaN system, were proposed and studied in the frequency band from $10 \mathrm{MHz}$ to $114.5 \mathrm{GHz}$. The switches were integrated into the coplanar waveguide, which allows them to be used in any system without the use of, e.g., bonding, flip-chip and other technologies and avoiding the matching problems. The on-state insertion losses for the designed switches were measured to range from 7.4 to $19.4 \mathrm{~dB}$, depending on the frequency and switch design. Although, at frequencies above $70 \mathrm{GHz}$, the switches were less effective, the switching effect was still evident with an approximately $4 \mathrm{~dB}$ on-off ratio. The best switches exhibited rise and fall switching times of $\sim 25 \mathrm{~ns}$ and $\sim 17 \mathrm{~ns}$, respectively. The use of such a switch can provide up to $20 \mathrm{MHz}$ of bandwidth in time-modulated systems, which is an outstanding result for such systems. The proposed equivalent circuit describes well the switching characteristics and can be used to design switches with required parameters.
\end{abstract}

Keywords: AlGaN/GaN; graphene; switches; two-dimensional high-density electron gas; millimeterwave devices

\section{Introduction}

Radio frequency (RF) and terahertz dynamically reconfigurable multi-element devices often require electronic switches. Efficient switches are important components for the development of new communication, sensing, imaging, testing, and instrumentation systems. Applications of such switches include switched-beam reconfigurable antennas, polarization switching, multi-band receivers, transceivers, time division duplexing systems, and test circuits with multiple signal paths.

There are a number of technologies available for millimeter-wave switches. Most of them employ transistors based on typical semiconductor manufacturing technologies using silicon or III-V semiconductors [1-11]. Besides these, there are less conventional technologies available, such as micro-electro-mechanical systems (MEMS) $[12,13]$ and switches based on phase changing materials (PCM) [14,15].

Graphene and transition metal dichalcogenides also attract attention for designing $\mathrm{RF}$ and terahertz switches and other devices [16,17]. A monolayer $\mathrm{MoS}_{2} \mathrm{RF}$ switch with a 0-50 GHz operating frequency range was reported in [18]. Several publications consider 
the possibilities of graphene-based RF switches for the millimeter-wave band [19-22]. However, these papers include only theoretical analysis and/or computer simulations.

Graphene can be also used to construct nanoelectro-mechanical systems (NEMS). This concept was investigated in [23-25]. The switches were based on a graphene membrane suspended over a specially constructed coplanar waveguide (CPW). When a bias voltage was applied, the membrane bent and created a short circuit in the waveguide.

Considering variable attenuators as a specific kind of switch, one can notice more examples of graphene-based devices. In [26], a prototype of a controllable attenuator based on graphene integrated with an antenna system was designed, fabricated, and measured. The attenuator allows beam steering at mm-wave frequencies. In [27], a novel tunable grounded CPW attenuator based on graphene nanoplates was also proposed. Further examples of graphene-based CPW and microstrip line attenuators can be found in $[28,29]$, respectively.

Graphene-based modulators should be also mentioned, since they can be based on switches [30-33].

What is common in the abovementioned publications on graphene-based switches is that graphene is used as an active switching element: a change in the graphene properties under bias allows the RF power to be switched.

In this paper, we propose and study an approach wherein the combination of graphene and two-dimensional high-density electron gas (2DEG) in the AlGaN/GaN system allows us to switch effectively at RF and $\mathrm{mm}$-wave frequencies. The switch was integrated into the planar transmission line. A CPW was chosen because it has smaller losses in comparison with the microstrip line. This approach allowed us to avoid the problems with packaging and interconnects, which can cause high losses, especially at mm waves.

\section{Structure of Graphene/AlGaN/GaN Switch and DC Characteristics}

The proposed hybrid structure includes a CPW with an embedded graphene/AlGaN/ $\mathrm{GaN}$ switch. A typical CPW consists of two ground conductors and a signal conductor line in the middle. In the proposed structure, the signal conductor line is made of $\mathrm{Ti} / \mathrm{Al} / \mathrm{Ni} / \mathrm{Au}$ on the top of the $\mathrm{AlGaN} / \mathrm{GaN}$ structure. The signal line is interrupted in the middle and the graphene gate device is placed in the gap between two parts of the signal line (see Figure 1). In the on state, the connection between two parts of the signal line is provided by 2DEG. The graphene layer in the middle of the device, above 2DEG, acts as a gate. The graphene gate is connected to the ground (GND) of the CPW; therefore, the device is controlled by the bias voltage applied to the CPW signal pads along with a high-frequency signal. As a result, the structure operates as a high-frequency single pole, single throw (SPST) switch.

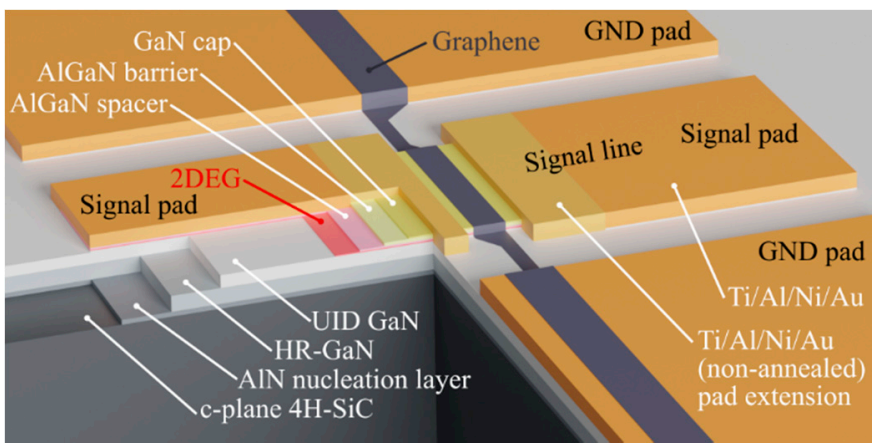

(a)

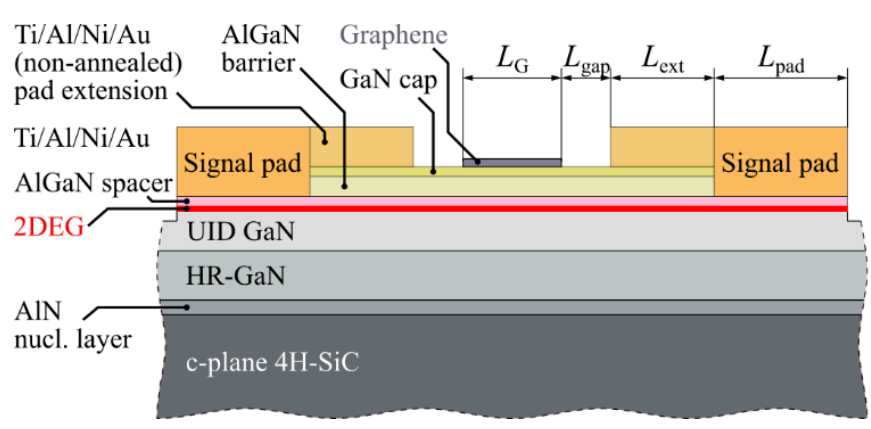

(b)

Figure 1. (a) Cutaway view of the structure; (b) cross-section along the constructed coplanar waveguide (CPW).

As opposed to a conventional transistor-based design, where a metal gate is used, the properties of a graphene gate also change when the voltage is applied between the graphene gate and 2DEG. Therefore, the properties of both the 2DEG and graphene are 
controlled by the bias. In other words, the 2DEG also can be considered as a "gate" relative to graphene. Since CVD graphene is of p-type conductivity, a positive voltage on the 2DEG relative to graphene reduces the concentration of holes and increases the graphene resistivity [34]. Therefore, with properly designed graphene and two-dimensional electron gas at the AlGaN/GaN interface, a positive voltage on the 2DEG relative to graphene can completely remove the conductive layers in the central line gap of the CPW. This should improve the off-state characteristics.

We used AlGaN/GaN epitaxial heterostructures grown by Metalorganic Vapor Phase Epitaxy (MOVPE) on a silicon carbide substrate. MOVPE growth was started from a 38-nm-thick AlN nucleation layer on a commercially available $500-\mu \mathrm{m}$-thick semi-insulating $\mathrm{SiC}$ substrate. The next layer was $2.3 \mu \mathrm{m}$ high-resistivity (HR) GaN buffer followed by a $0.7 \mu \mathrm{m}$ unintentionally doped (UID) GaN layer. The AlGaN barrier consisted of: $1.2 \mathrm{~nm} \mathrm{Al} \mathrm{Ga}_{1-x} \mathrm{~N}(x=66 \%), 5 \mathrm{~nm} \mathrm{Al} \mathrm{Ga}_{1-x} \mathrm{~N}$ UID $(x=28 \%), 10 \mathrm{~nm}$ AlGaN:Si $\left(\mathrm{n} \sim 1.5 \times 10^{18} \mathrm{~cm}^{-3}\right)$, and a $2 \mathrm{~nm}$ UID AlGaN layer. The whole heterostructure was covered by a $2 \mathrm{~nm} \mathrm{GaN}$ cap layer. A schematic diagram of the fabricated heterostructures is shown in Figure 1. This is a typical structure of $\mathrm{AlGaN} / \mathrm{GaN}$ high electron mobility transistors (HEMTs) for high-frequency applications [32].

The CPW processing was performed using a commercial laser writer system for lithography based on a $405 \mathrm{~nm}$ wavelength GaN laser source with a minimum $1 \mu \mathrm{m}$ linewidth. The first step in the processing was $150 \mathrm{~nm}$ mesa etching provided by an Inductively Coupled Plasma-Reactive Ion Etching system. As a result of the etching, the 2DEG remained only under the signal line. Then, ohmic contacts were formed by thermal evaporation of $\operatorname{Ti}(15 \mathrm{~nm}) / \mathrm{Al}(100 \mathrm{~nm}) / \mathrm{Ni}(40 \mathrm{~nm}) / \mathrm{Au}(50 \mathrm{~nm})$ and rapid thermal annealing at $780^{\circ} \mathrm{C}$ for $1 \mathrm{~min}$ under a $\mathrm{N}_{2}$ atmosphere. Metallization for the ohmic contacts was deposited on the central line and interrupted in the middle. The ground lines were fabricated simultaneously. In order to be able to tune the width of the gap in the central line, the same $\mathrm{Ti} / \mathrm{Al} / \mathrm{Ni} / \mathrm{Au}$ metal stack may be deposited at a later time in order to reduce the gap width. This metal stack was not annealed.

The last step was graphene transferring and its patterning. A chemical vapor deposition (CVD) graphene layer was deposited on the whole GaN-based wafer by the high-speed electrochemical delamination technique [35]. The detailed step-by-step procedure of the graphene delamination and transferring from $\mathrm{Cu}$ foil onto AlGaN/GaN can be found in [36]. Finally, graphene patterning was performed by oxygen plasma etching. Graphene remained in the central line gap and was extended to the ground pads as shown in Figure 1a. A cross-section of the structure is shown in Figure 1b.

During the CPW fabrication, the quality of the graphene layer was controlled with Raman spectroscopy. Figure 2 shows the Raman spectra of graphene transferred onto the $\mathrm{AlGaN} / \mathrm{GaN}$ wafer, recorded with a Renishaw inVia micro-Raman system using a $532 \mathrm{~nm}$ frequency doubled Nd:YAG laser as an excitation source. The typical graphene peaks were observed: G mode at $1590 \mathrm{~cm}^{-1}$ and 2D mode at $2685 \mathrm{~cm}^{-1}$, which are characteristic of the $\mathrm{sp}^{2}$ hybridization of carbon. The full width at half maximum (FWHM) of the 2D band and the intensity ratio of the $2 \mathrm{D} / \mathrm{G}$ peaks were used to determine the number of graphene layers and their quality. The FWHM of the 2D peak in Figure 2 was $\sim 34 \mathrm{~cm}^{-1}$, which is typical for monolayer graphene. The ratio $\mathrm{I}_{2 \mathrm{D}} / \mathrm{I}_{\mathrm{G}}$ was over 2 , which is characteristic of a monolayer of graphene as well. The obtained results confirmed that the graphene sample was of high quality and defect-free. The spectrum in the range from $1050 \mathrm{~cm}^{-1}$ to $1950 \mathrm{~cm}^{-1}$ showed also features stemming from the SiC substrate. 


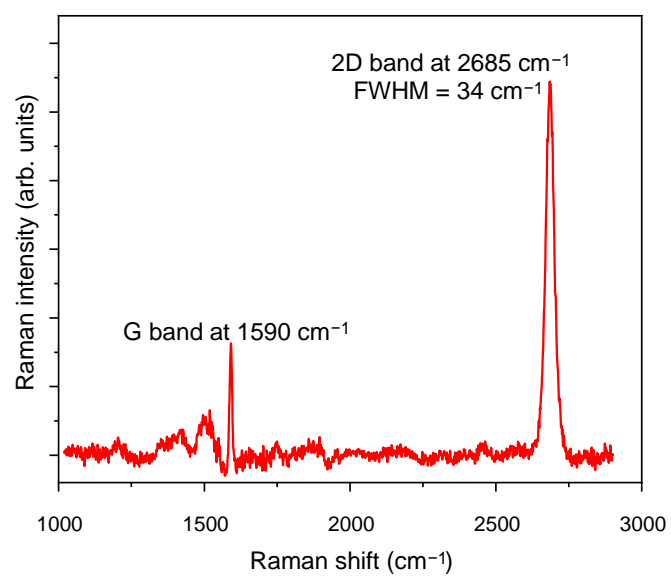

Figure 2. Raman spectrum of the graphene layer on the AlGaN/GaN wafer grown on SiC substrate.

The optical microscope images of three of the fabricated devices are shown in Figure 3. Since graphene is barely seen in an optical microscope, its location is outlined with red dashed lines. The dark color corresponds to the annealed contact metallization, and the lighter color is the metallization deposited at the second step. The dimensions of the structures are summarized in Table 1.

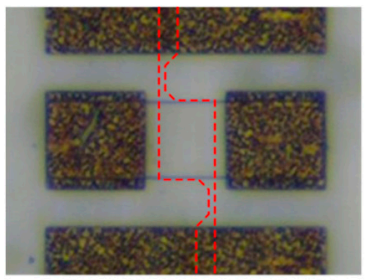

E4

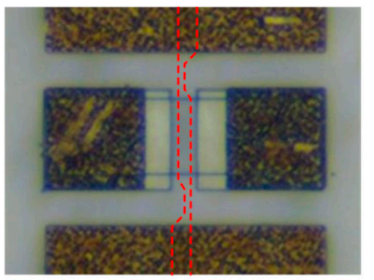

E1

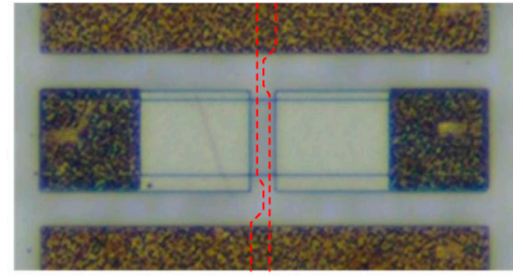

G1

Figure 3. Fabricated graphene/AlGaN/GaN RF switches.

Table 1. Dimensions of the graphene/AlGaN/GaN switches.

\begin{tabular}{ccccc}
\hline Structure & $\boldsymbol{L}_{\mathbf{G}}$ & $\boldsymbol{L}_{\text {gap }}$ & $\boldsymbol{L}_{\text {ext }}$ & $\boldsymbol{L}_{\text {pad }}$ \\
\hline $\mathrm{E} 4$ & $45 \mu \mathrm{m}$ & $10 \mu \mathrm{m}$ & $0 \mu \mathrm{m}$ & $80 \mu \mathrm{m}$ \\
$\mathrm{E} 1$ & $10 \mu \mathrm{m}$ & $5 \mu \mathrm{m}$ & $22.5 \mu \mathrm{m}$ & $80 \mu \mathrm{m}$ \\
$\mathrm{G} 1$ & $10 \mu \mathrm{m}$ & $5 \mu \mathrm{m}$ & $90 \mu \mathrm{m}$ & $80 \mu \mathrm{m}$ \\
\hline
\end{tabular}

The structures shown in Figure 3 represent the field effect transistors with the left and right sides of the central line acting as the source and drain. The graphene layer in the middle, which is located between the source and drain on the top of the AlGaN barrier layer, acts as a gate. It was shown previously [36] that graphene forms a high-quality Schottky barrier to AlGaN and graphene gate AlGaN/GaN transistors demonstrate very good characteristics. Figure 4 shows the transfer current-voltage characteristics of the transistor in the E4 structure. The transistors demonstrated around six orders of magnitude for the on-off ratio and the subthreshold slope $n=1.3-1.4$. The subthreshold current, which is determined by the gate leakage current, was very small, even for the transistor with the highest gate area, as shown in Figure 4. The current-voltage characteristic shown in the linear scale in Figure 4 only slightly tends to saturate at high gate voltages, indicating the minor contribution of the contact resistance. The threshold voltage for the studied transistors determined from the linear extrapolation of the current-voltage characteristic at a small drain voltage was within the range of $\mathrm{V}_{\mathrm{t}}=-3.0$ to $-3.2 \mathrm{~V}$. This means that at $\mathrm{V}_{\mathrm{g}}<-3.5 \mathrm{~V}$, the channel is fully depleted and the transmission line is interrupted. It is connected only due to the highly resistive graphene layer and fringing capacitances. At zero gate voltage, the central line is connected by the highly conductive 2DEG. 


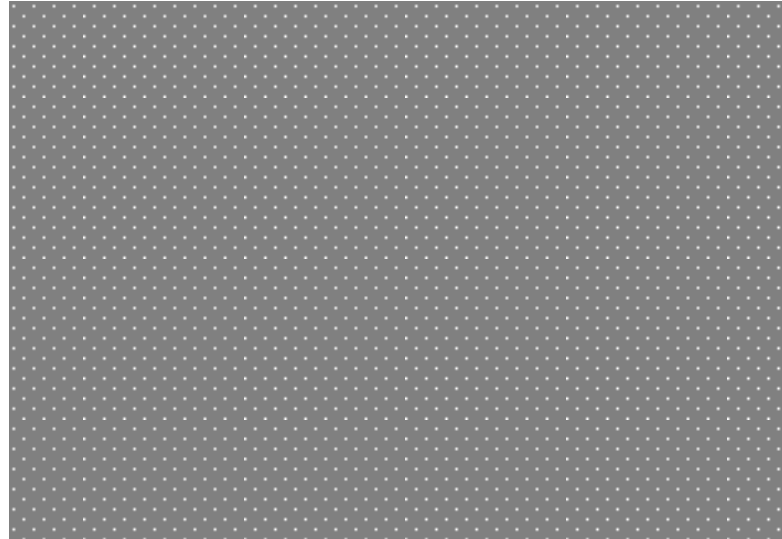

Figure 4. Transfer current-voltage characteristics of the transistor in E4 structure. Drain voltage $\mathrm{V}_{\mathrm{d}}=0.1 \mathrm{~V}$.

\section{RF Characteristics}

On-chip S-parameter measurements of the graphene/AlGaN/GaN switches in the 70.5-114.5 GHz frequency range were carried out using a measurement setup configured as shown in Figure 5. The setup consisted of the Agilent N5245A PNA-X vector network analyzer (VNA) with VDI WR-10 waveguide frequency extenders and $100 \mu \mathrm{m}$ pitch Cascade Microtech Infinity WR-10 waveguide GSG probes. The probes were positioned using the Cascade Microtech EPS200MMW probe station. For the measurements at frequencies below $50 \mathrm{GHz}$, the same setup was used but without frequency extenders and with coaxial GSG probes. Figure 6 shows an optical microscope image of the structure under testing with the probes attached.

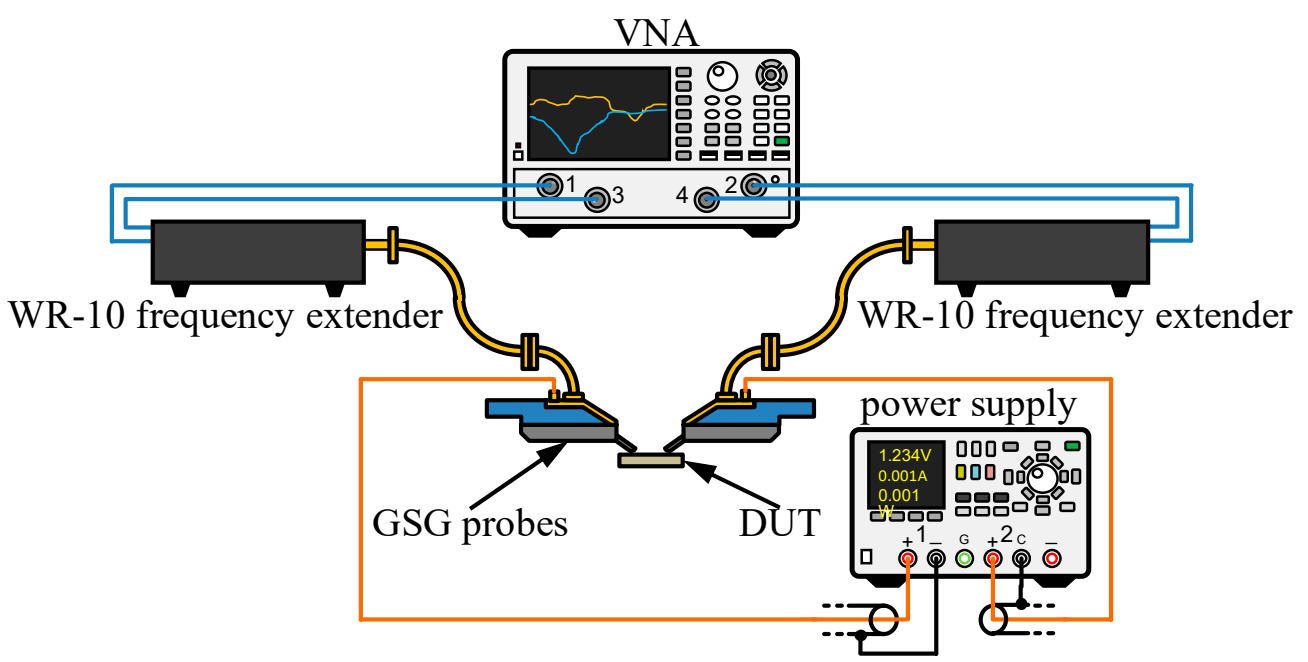

Figure 5. Schematic diagram of the measurement setup (DUT stands for "device under test").

For the calibration and setting of the measurement plane to the contact pads, the SOLR Cascade 101-190C and LRM Cascade 138-357 standard impedance substrates were used at low and high frequencies, respectively. The S-parameter measurements were performed with bias voltages applied between the central lines and ground. The DC connections were provided through the bias ports of the VNA and through the bias ports of the waveguide probes in the low- and high-frequency configurations, respectively. As the graphene layer was connected to the GND conductors (Figure 1a), a positive voltage applied to the signal pads corresponded to the negative bias of the graphene gate. 


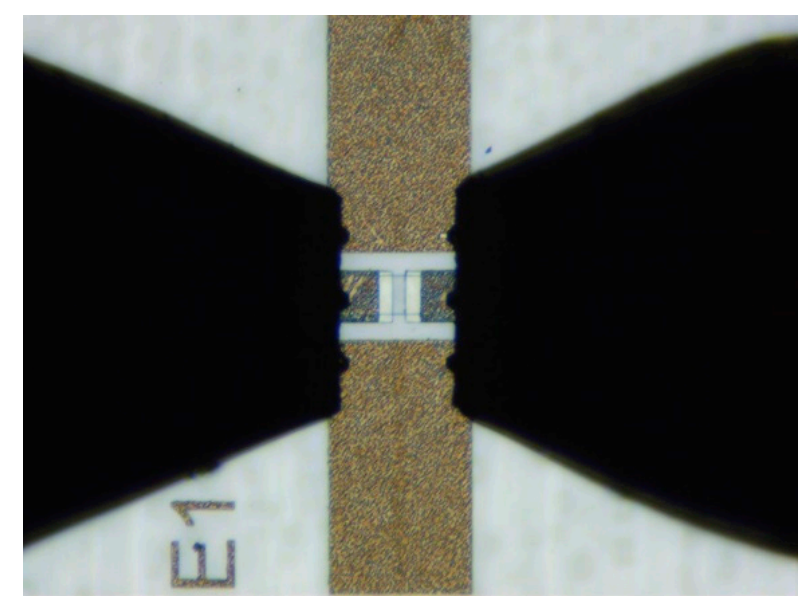

Figure 6. Microscopic view of graphene/AlGaN/GaN switch with probes attached.

Figure 7 shows the measured transmission coefficient S21 characteristics in the on and off state of three examined graphene/AlGaN/GaN switches (see Table 1 for details). In the studied configuration, the on state corresponds to zero gate voltage and the off state was studied at $\mathrm{V}_{\mathrm{g}}=-5 \mathrm{~V}$.

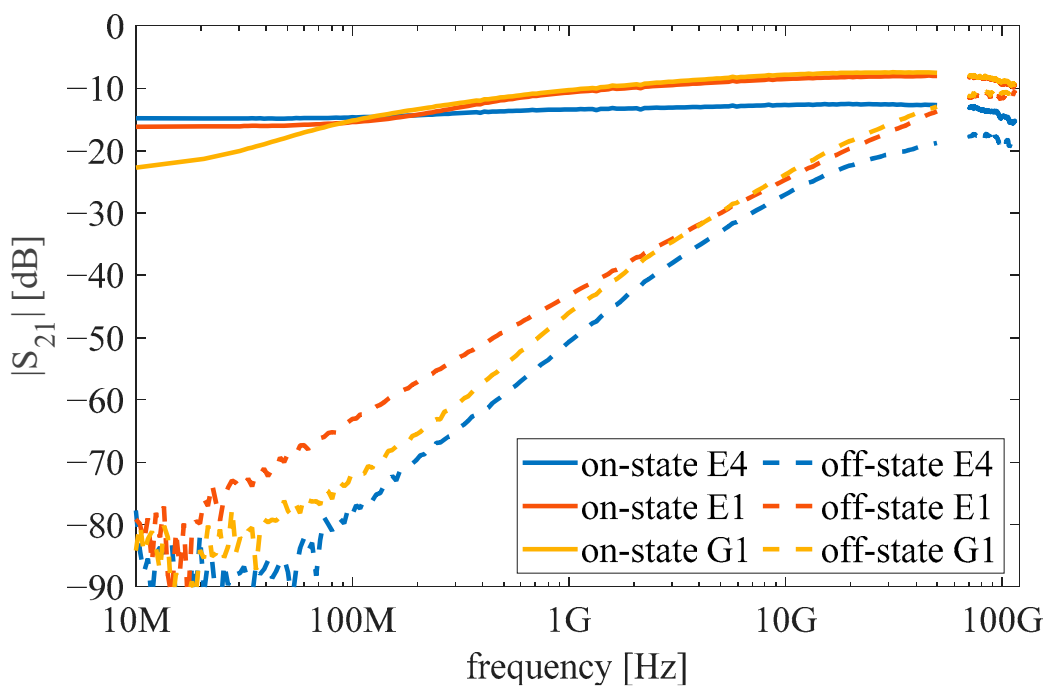

Figure 7. Measured transmission coefficient characteristics of the graphene/AlGaN/GaN switches.

The structure E4 with the large gap in the central line $L=2 L_{\text {gap }}+L_{\mathrm{g}}=65 \mu \mathrm{m}$ exhibits insertion loss between 12.5 and $14.9 \mathrm{~dB}$ in the on state across a very wide frequency range. On the other hand, the off-state characteristics show the strong frequency dependence of isolation, which is typical for parasitic capacitive coupling. Isolation values decrease from over $77 \mathrm{~dB}$ below $100 \mathrm{MHz}$ to $17.5-19.4 \mathrm{~dB}$ in the 70.5-114.5 GHz frequency range. Despite poor isolation at frequencies above $70 \mathrm{GHz}$, the switching effect is still evident, with an on-off ratio of approximately $4 \mathrm{~dB}$.

Narrowing the gap in the central line to $L=2 L_{\text {gap }}+L_{g}=20 \mu \mathrm{m}$ in the E1 and G1 structures allowed us to achieve lower on-state insertion loss (7.4-14.1 dB) at frequencies above $200 \mathrm{MHz}$. A smaller gap between extended pads has an adverse impact on the isolation due to increased capacitive coupling between the input and output. As a result, at frequencies above $\sim 100 \mathrm{GHz}$, switching is not effective. E1 and G1 structures have different dimensions of extension pads, which causes their slightly different behavior at low frequencies. 
In order to study the switching properties in the time domain, the DC power supplier was replaced with the function generator.

Figure 8 shows the switching dynamics of a $1 \mathrm{GHz}$ signal at the output. The waveforms presented in Figure 8 were obtained with $100 \mathrm{kHz}$, with a $5 \mathrm{~V}$ square wave signal applied to the structures.

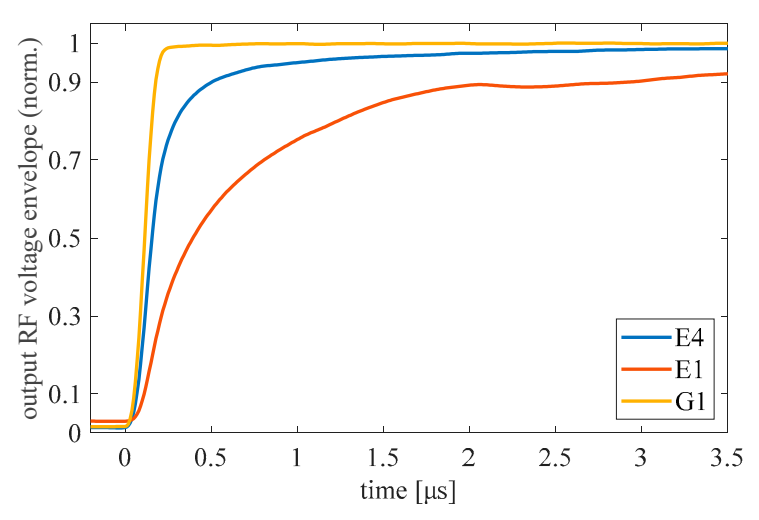

(a)

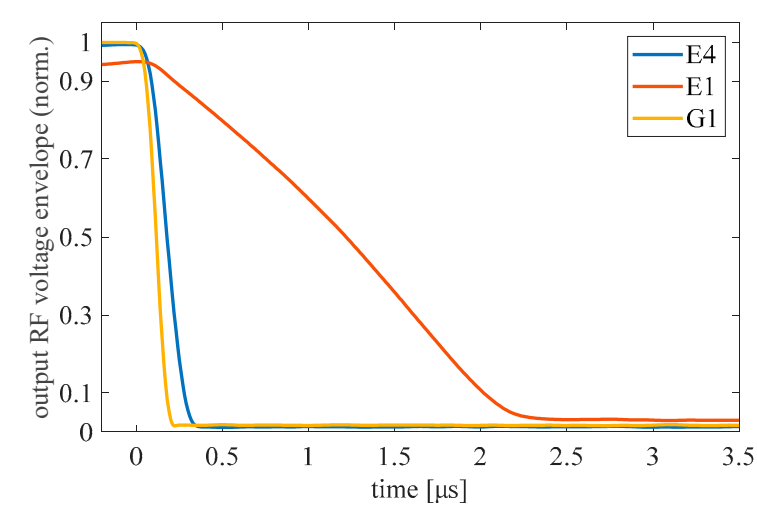

(b)

Figure 8. Turn-on (a) and turn-off (b) transient behavior of output RF voltage envelope of the graphene/AlGaN/GaN switches measured at $1 \mathrm{GHz}$. The waveforms are normalized to their own amplitude in steady on state.

The measured switching times are listed in Table 2. The large differences in switching times between structures can be attributed to technological uncertainties, particularly to the graphene quality. The switch based on the G1 structure exhibits a very fast switching time. The rise and fall times are $25 \mathrm{~ns}$ and $17 \mathrm{~ns}$, respectively. The use of such a switch can provide up to $20 \mathrm{MHz}$ of bandwidth in time-modulated systems, which is an outstanding result for such systems $[10,37]$.

Table 2. Measured switching times (between $10 \%$ and $90 \%$ of the RF voltage).

\begin{tabular}{ccc}
\hline Structure & Rise Time & Fall Time \\
\hline E4 & $360 \mathrm{~ns}$ & $120 \mathrm{~ns}$ \\
E1 & $2900 \mathrm{~ns}$ & $1750 \mathrm{~ns}$ \\
G1 & $25 \mathrm{~ns}$ & $17 \mathrm{~ns}$ \\
\hline
\end{tabular}

The measured transmission characteristics shown in Figure 7 were compared with the characteristics of an equivalent small-signal circuit of the structures shown in Figure 9a. The circuit represents the physical design of the structure.

The graphene gate is represented by resistors R5-R4-R5 arranged according to the gate shape (Figure 9b). The graphene gate and 2DEG underneath constitute a capacitor with resistive plates, which is represented as an element R3-C3-R4. This element is actually a distributed capacitor and it is modeled as an infinite number of elementary stages dR3dC3-dR4, connected as shown in Figure 9a. The values of R3-C3-R4 elements are the sums of their elemental counterparts. Two capacitors $\mathrm{C} 2$ represent the fringe capacitances of the graphene gate (mainly responsible for limited isolation in the off state).

Similarly, pad extension with 2DEG underneath constitutes a capacitor with a single resistive plate R1-C1. Values of circuit elements are given in Table 3. They were extracted from nominal structure parameters and DC current-voltage characteristics, except for C2, which was matched based on the measured data.

The comparison of measurements and simulations of the S11 and S21 parameters for the G1 structure is presented in Figure 10. For both reflectivity (S11) and transmission (S21), the simulation corresponds to the measurement in both operating states. Simulations of the E4 and E1 structures also showed good agreement with the measurements. 


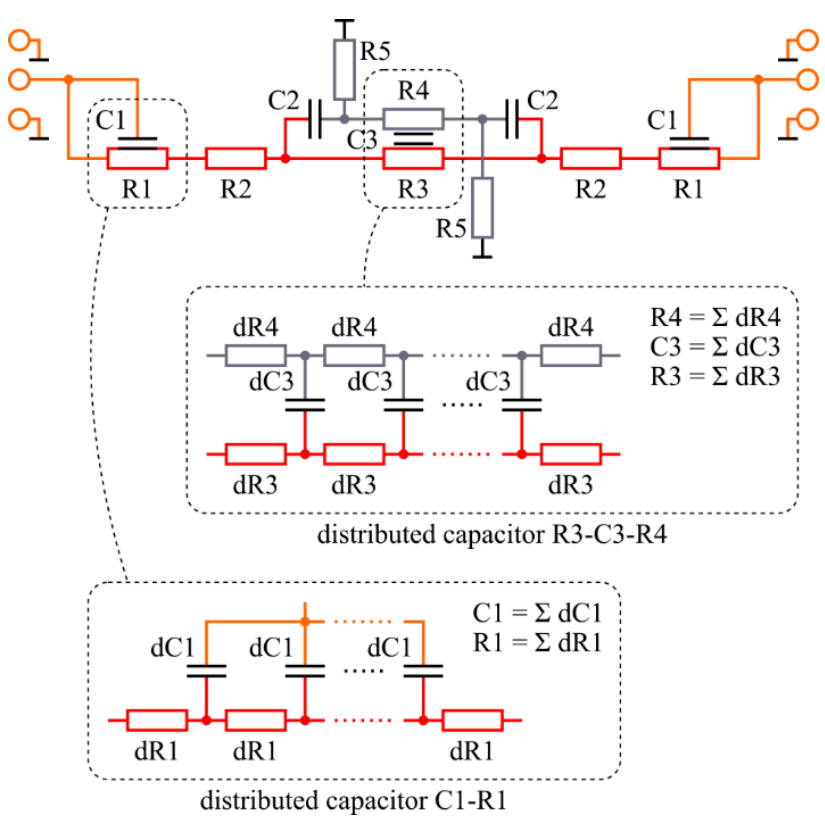

(a)

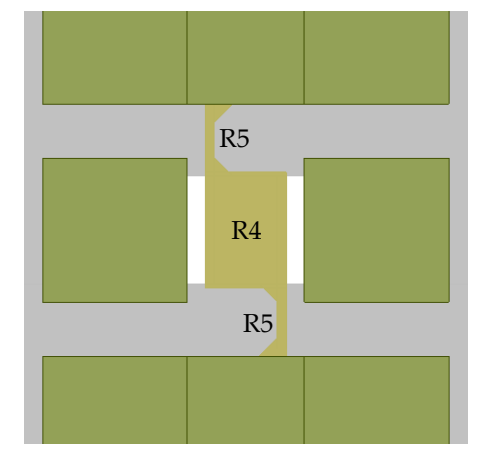

(b)

Figure 9. (a) Equivalent small-signal circuit for both on and off states. Colors refer to the physical structure: red-2DEG, orange-contact pads and its extensions, gray-graphene. (b) Schematic view of the switch with indicated resistances of graphene, R4, and R5.

Table 3. Equivalent schematic element values extracted from nominal structure parameters and DC characteristics.

\begin{tabular}{|c|c|c|c|c|c|c|c|c|c|}
\hline Structure & State & R1 & $\mathrm{C} 1$ & R2 & R3 & $\mathrm{C} 2$ & $\mathrm{C} 3$ & R4 & R5 \\
\hline E4 & $\begin{array}{l}\text { ON } \\
\text { OFF }\end{array}$ & $0 \Omega$ & $0 \mathrm{pF}$ & $50 \Omega$ & $\begin{array}{c}320 \Omega \\
\infty\end{array}$ & $16 \mathrm{fF}$ & $11.8 \mathrm{pF}$ & $1 \mathrm{k} \Omega$ & $8 \mathrm{k} \Omega$ \\
\hline E1 & $\begin{array}{l}\text { ON } \\
\text { OFF }\end{array}$ & $160 \Omega$ & $5.9 \mathrm{pF}$ & $45 \Omega$ & $\begin{array}{c}72 \Omega \\
\infty\end{array}$ & $22 \mathrm{fF}$ & $2.6 \mathrm{pF}$ & $233 \Omega$ & $8 \mathrm{M} \Omega$ \\
\hline G1 & $\begin{array}{l}\text { ON } \\
\text { OFF }\end{array}$ & $645 \Omega$ & $24 \mathrm{pF}$ & $45 \Omega$ & $\begin{array}{c}72 \Omega \\
\infty\end{array}$ & $22 \mathrm{fF}$ & $2.6 \mathrm{pF}$ & $233 \Omega$ & $8 \mathrm{k} \Omega$ \\
\hline
\end{tabular}

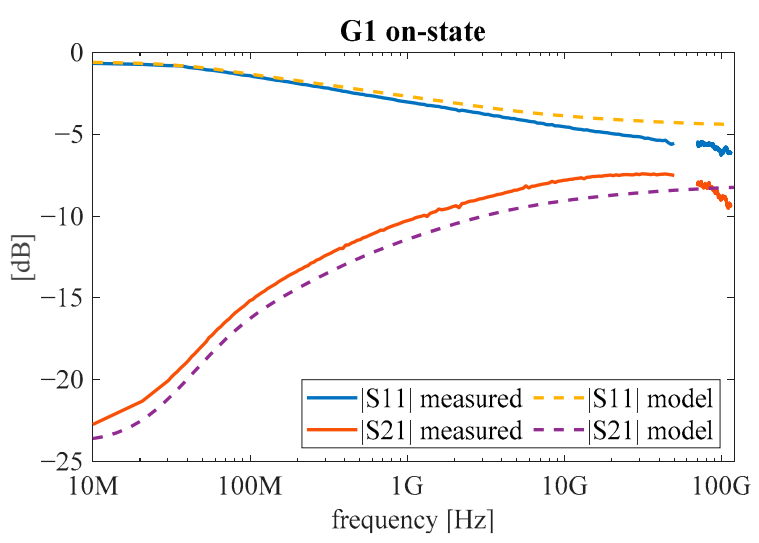

(a)

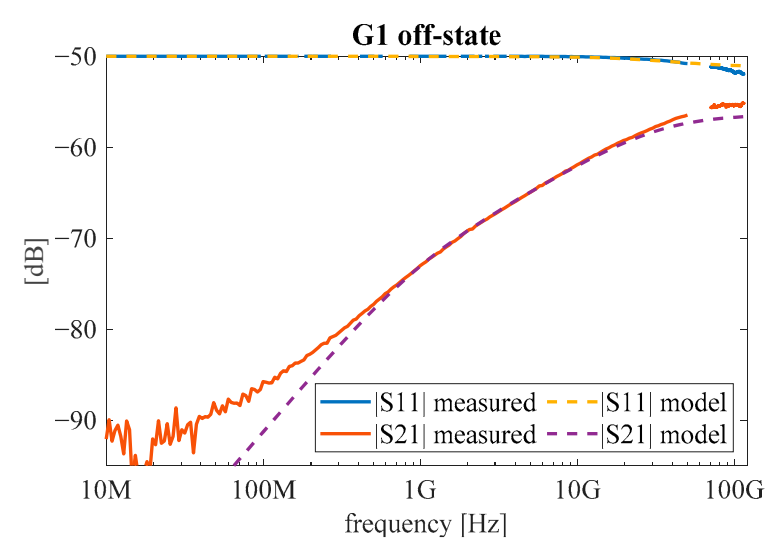

(b)

Figure 10. S11 and S21 scattering parameters for the G1 structure calculated from equivalent small-signal circuit along with measurement results for (a) on and (b) off states.

The results of simulations shown in Figure 10 indicate that the proposed equivalent circuit represents well the behavior of the studied graphene switches and can be used for the designing of switches with required parameters. 


\section{Discussion}

Table 4 compares the parameters of the studied switches with previously published results for graphene-based RF switches. As can be seen, the graphene/AlGaN/GaN switches demonstrate very good characteristics, in many ways better than other published simulated and experimental results. The proposed devices operate with a low driving voltage and very low power consumption, providing very fast switching. As seen in Table 4, this kind of graphene-based switch is one of the very few switches whose parameters have been studied experimentally.

Table 4. State of the art for graphene-based RF switches.

\begin{tabular}{|c|c|c|c|c|c|c|c|c|}
\hline Ref. & Configuration & $\begin{array}{l}\text { Max. } \\
\text { Freq. } \\
\text { (GHz) }\end{array}$ & $\begin{array}{l}\text { Insertion } \\
\text { Loss (dB) }\end{array}$ & $\begin{array}{l}\text { Isolation } \\
\text { (dB) }\end{array}$ & $\begin{array}{l}\text { Rise/Fall } \\
\text { Time (ns) }\end{array}$ & $\begin{array}{l}\text { Control } \\
\text { Voltage } \\
\text { (V) }\end{array}$ & Driving Current (mA) & $\begin{array}{l}\text { Validation } \\
\text { of the } \\
\text { Results }\end{array}$ \\
\hline [19] & $\begin{array}{l}\text { graphene } \\
\text { shunt with } \\
\text { graphene gate }\end{array}$ & 60.8 & 1.1 & 34.5 & $\mathrm{n} / \mathrm{a}$ & 33 & $\sim 0$ (isolated gate) & $\begin{array}{l}\text { simulation } \\
\text { study }\end{array}$ \\
\hline [20] & $\begin{array}{l}\text { graphene } \\
\text { shunt }\end{array}$ & 70 & 5 & $>33$ & $\mathrm{n} / \mathrm{a}$ & 30 & $\mathrm{n} / \mathrm{a}$ & $\begin{array}{l}\text { simulation } \\
\text { study }\end{array}$ \\
\hline$[23,24]$ & $\begin{array}{l}\text { graphene } \\
\text { NEMS shunt }\end{array}$ & 60 & 0.2 & $>20$ & $\mathrm{n} / \mathrm{a}$ & 7 & $\sim 0$ (isolated membrane) & $\begin{array}{l}\text { simulation } \\
\text { study }\end{array}$ \\
\hline [25] & $\begin{array}{l}\text { graphene } \\
\text { NEMS shunt }\end{array}$ & 110 & 1.2 & $<15$ & $\mathrm{n} / \mathrm{a}$ & $\mathrm{n} / \mathrm{a}$ & $\sim 0$ (isolated membrane) & $\begin{array}{l}\text { simulation } \\
\text { study }\end{array}$ \\
\hline [27] & $\begin{array}{c}\text { graphene } \\
\text { shunt } \\
\text { (attenuator) }\end{array}$ & 28 & 2.5 & 14 & $\mathrm{n} / \mathrm{a}$ & 6 & 65 & measurement \\
\hline [28] & $\begin{array}{c}\text { graphene } \\
\text { shunt } \\
\text { (attenuator) }\end{array}$ & 40 & 3 & $11.5-15$ & $\mathrm{n} / \mathrm{a}$ & 4 & $\mathrm{n} / \mathrm{a}$ & measurement \\
\hline $\begin{array}{l}\text { This } \\
\text { work }\end{array}$ & $\begin{array}{l}\text { 2DEG series } \\
\text { circuit with } \\
\text { graphene gate }\end{array}$ & $84^{1}$ & $7.4-19.4$ & $17.5-77$ & $25 / 17$ & 5 & $\sim 0$ (isolated gate) & measurement \\
\hline
\end{tabular}

${ }^{1}$ The max. frequency is calculated as cut-off frequency $f_{\text {cut-off }}=1 /\left(2 \pi \cdot \mathrm{R}_{\mathrm{on}} \cdot \mathrm{C}_{\text {off }}\right)$, where $\mathrm{C}_{\text {off }}=\frac{1}{2} \cdot \mathrm{C} 2, \mathrm{R}_{\text {on }}=\mathrm{R} 3+2 \cdot \mathrm{R} 2+2 \cdot \mathrm{R}(\mathrm{R} 1-\mathrm{C} 1), \mathrm{R}(\mathrm{R} 1-\mathrm{C} 1)$ is the resistance of R1-C1 circuit at cut-off frequency. For the E1 and G1 structures, R(R1-C1) $\approx 5 \Omega$ at $84 \mathrm{GHz}$. The values of C2, R2, and R3 are given in Table 3 . For the E4 structure, $f_{\text {cut-off }}=47 \mathrm{GHz}$.

Although the switches in more conventional technologies demonstrate better highfrequency performance, this research is in the early stage and there is room for improvement. The advantage of the application of graphene as a gate in a millimeter-wave switch is that its parameters change with bias at the same time as the channel parameters. Therefore, in the off state, with positive bias on the 2DEG relative to the graphene gate, the conductive layers can be eliminated from the gap in the CPW, making the impact of parasitic connection through fringing capacitances and the gate less significant. The main directions of the future development of this type of structure are the optimization of graphene characteristics and switch geometry as well as the evaluation of shunt architecture to achieve lower insertion losses and a higher operating frequency band.

\section{Conclusions}

We have proposed and studied the design of a switch that uses a combination of graphene and two-dimensional high-density electron gas (2DEG) in an AlGaN/GaN system in order to provide effective switching at RF frequencies. The switch was integrated into the coplanar waveguide, which was chosen due to lower losses compared to the microstrip line, especially at high frequencies. The presented design is an on-chip solution fabricated in one technological process. The proposed equivalent circuit describes well the switching characteristics and can be used to design switches with required parameters. The switching times are sufficiently low to use this kind of switch in time-modulated systems. 
Author Contributions: Conceptualization, Y.Y., S.R. and G.C.; methodology, Y.Y. and P.B.; formal analysis, W.K., S.R. and G.C.; investigation, P.B., J.S., A.P., A.K. and M.D.; resources, P.S. and P.P.; writing-original draft preparation, P.B., J.S. and A.K.; writing-review and editing, all authors; visualization, P.B. and J.S.; supervision, W.K.; project administration, Y.Y., S.R. and G.C.; funding acquisition, W.K., G.C. and A.K. All authors have read and agreed to the published version of the manuscript.

Funding: This work was partially supported by the "International Research Agendas" program of the Foundation for Polish Science, cofinanced by the European Union under the European Regional Development Fund (number MAB/2018/9) and by the National Science Centre, Poland, allocated on the basis of grant numbers 2016/22/E/ST7/00526, 2019/35/N/ST7/00203, and 2017/27/L/ST7/03283. This work is part of a project that has received funding from the European Union's Horizon 2020 research and innovation programme under the Marie Skłodowska-Curie grant agreement No 778156. A.K. was supported by the Foundation for Polish Science (FNP) under grant number START 44.2021.

Institutional Review Board Statement: Not applicable.

Informed Consent Statement: Not applicable.

Conflicts of Interest: The authors declare no conflict of interest. The funders had no role in the design of the study; in the collection, analyses, or interpretation of data; in the writing of the manuscript, or in the decision to publish the results.

\section{References}

1. Kim, J.; Kim, S.; Song, K.; Rieh, J.-S. A 300-GHz SPST Switch with a New Coupled-Line Topology in 65-nm CMOS Technology. IEEE Trans. Terahertz Sci. Technol. 2019, 9, 215-218. [CrossRef]

2. Tawfik, Y.; Raju, A.; Varonen, M.; Najmussadat, M.; Halonen, K.A.I. 250 GHz SiGe SPDT Resonator Switch. In Proceedings of the 2020 15th European Microwave Integrated Circuits Conference (EuMIC), Utrecht, The Netherlands, 10-15 January 2021; pp. 289-291.

3. Schmid, R.L.; Ulusoy, A.C.; Song, P.; Cressler, J.D. A 94 GHz, 1.4 dB Insertion Loss Single-Pole Double-Throw Switch Using Reverse-Saturated SiGe HBTs. IEEE Microw. Wirel. Components Lett. 2013, 24, 56-58. [CrossRef]

4. Yi, C.; Choi, S.H.; Urteaga, M.; Kim, M. 20-Gb/s ON-OFF-Keying Modulators Using 0.25- $\mu$ m InP DHBT Switches at 290 GHz. IEEE Microw. Wirel. Components Lett. 2019, 29, 360-362. [CrossRef]

5. Thome, F.; Brückner, P.; Quay, R.; Ambacher, O. Millimeter-Wave Single-Pole Double-Throw Switches Based on a 100-nm Gate-Length AlGaN/GaN-HEMT Technology. In Proceedings of the 2019 IEEE MTT-S International Microwave Symposium (IMS), Boston, MA, USA, 2-7 June 2019; pp. 1403-1406. [CrossRef]

6. Kim, Y.; Jeon, S. Mm-wave single-pole single-throw m-HEMT switch with low loss and high linearity. Electron. Lett. 2020, 56, 719-721. [CrossRef]

7. Song, P.; Schmid, R.L.; Ulusoy, A.Ç.; Cressler, J.D. A high-power, low-loss W-band SPDT switch using SiGe PIN diodes. In Proceedings of the 2014 IEEE Radio Frequency Integrated Circuits Symposium, Tampa, FL, USA, 1-3 June 2014; pp. 195-198. [CrossRef]

8. Yashchyshyn, Y.; Marczewski, J.; Tomaszewski, D. Investigation of the S-PIN Diodes for Silicon Monolithic Antennas with Reconfigurable Aperture. IEEE Trans. Microw. Theory Tech. 2010, 58, 1100-1106. [CrossRef]

9. Yashchyshyn, Y.; Marczewski, J.; Derzakowski, K.; Modelski, J.; Grabiec, P.B. Development and Investigation of an Antenna System With Reconfigurable Aperture. IEEE Trans. Antennas Propag. 2009, 57, 2-8. [CrossRef]

10. Yashchyshyn, Y.; Derzakowski, K.; Bajurko, P.; Marczewski, J.; Kozlowski, S. Time-Modulated Reconfigurable Antenna Based on Integrated S-PIN Diodes for mm-Wave Communication Systems. IEEE Trans. Antennas Propag. 2015, 63, 4121-4131. [CrossRef]

11. Yashchyshyn, Y.; Derzakowski, K.; Bogdan, G.; Godziszewski, K.; Nyzovets, D.; Kim, C.H.; Park, B. 28 GHz Switched-Beam Antenna Based on S-PIN Diodes for 5G Mobile Communications. IEEE Antennas Wirel. Propag. Lett. 2017, 17, 225-228. [CrossRef]

12. Wipf, S.T.; Goritz, A.; Wietstruck, M.; Wipf, C.; Tillack, B.; Kaynak, M. D-Band RF-MEMS SPDT Switch in a $0.13 \mu \mathrm{m}$ SiGe BiCMOS Technology. IEEE Microw. Wirel. Components Lett. 2016, 26, 1002-1004. [CrossRef]

13. Heredia, J.; Ribo, M.; Pradell, L.; Wipf, S.T.; Goritz, A.; Wietstruck, M.; Wipf, C.; Kaynak, M. A 125-143-GHz FrequencyReconfigurable BiCMOS Compact LNA Using a Single RF-MEMS Switch. IEEE Microw. Wirel. Components Lett. 2019, 29 , 339-341. [CrossRef]

14. Borodulin, P.; El-Hinnawy, N.; Padilla, C.R.; Ezis, A.; King, M.R.; Johnson, D.R.; Nichols, D.T.; Young, R.M. Recent advances in fabrication and characterization of GeTe-based phase-change RF switches and MMICs. In Proceedings of the 2017 IEEE MTT-S International Microwave Symposium (IMS), Honololu, HI, USA, 4-9 June 2017; pp. 285-288. [CrossRef]

15. Hillman, C.; Stupar, P.A.; Hacker, J.B.; Griffith, Z.; Field, M.; Rodwell, M. An ultra-low loss millimeter-wave solid state switch technology based on the metal-Insulator-Transition of vanadium dioxide. In Proceedings of the 2014 IEEE MTT-S International Microwave Symposium (IMS2014), Tampa, FL, USA, 1-6 June 2014; pp. 1-4. [CrossRef] 
16. Zhang, J.; Zhu, W. Graphene-Based Microwave Metasurfaces and Radio-Frequency Devices. Adv. Photonics Res. $2021,2100142$. [CrossRef]

17. Theofanopoulos, P.C. Millimeter-Wave and Terahertz Reconfigurable Apertures for Imaging and Wireless Communication Applications. Ph.D. Thesis, Arizona State University, Tempe, AZ, USA, 2021.

18. Kim, M.; Park, S.; Sanne, A.; Banerjee, S.K.; Akinwande, D. Towards mm-wave nanoelectronics and RF switches using MoS 2 2D Semiconductor. In Proceedings of the 2018 IEEE/MTT-S International Microwave Symposium_IMS, Philadelphia, PA, USA, 10-15 June 2018; pp. 352-354. [CrossRef]

19. Yang, F.; Wu, X.; Guo, X.; Xu, Y. A design of SPDT switch using graphene device. In Proceedings of the 2015 IEEE International Symposium on Antennas and Propagation \& USNC/URSI National Radio Science Meeting, Vancouver, BC, USA, 19-24 July 2015; pp. 1658-1659. [CrossRef]

20. Pan, K.; Leng, T.; Zhang, X.; Hu, Z. Design and modeling of back gated graphene based RF switch with CPW transmission line on a high resistivity silicon substrate. In Proceedings of the 2017 10th UK-Europe-China Workshop on Millimetre Waves and Terahertz Technologies (UCMMT), Liverpool, UK, 11-13 September 2017; pp. 1-2. [CrossRef]

21. Theofanopoulos, P.C.; Trichopoulos, G.C. Modeling of Sub-Millimeter Wave Coplanar Waveguide Graphene Switches. In Proceedings of the 2019 IEEE International Symposium on Antennas and Propagation and USNC-URSI Radio Science Meeting, Atlanta, GA, USA, 7-12 July 2019; pp. 1527-1528. [CrossRef]

22. Theofanopoulos, P.C.; Trichopoulos, G.C. Modeling and Analysis of Terahertz Graphene Switches for On-Wafer Coplanar Transmission Lines. J. Infrared Millimeter Terahertz Waves 2020, 41, 758-775. [CrossRef]

23. Sharma, P.; Perruisseau-Carrier, J.; Moldovan, C.; Ionescu, A.M.; Sharma, P.; Perruisseau-Carrier, J.; Moldovan, C.; Ionescu, A.M. Electromagnetic Performance of RF NEMS Graphene Capacitive Switches. IEEE Trans. Nanotechnol. 2013, 13, 70-79. [CrossRef]

24. Sharma, P.; Perruisseau-Carrier, J.; Ionescu, A.M. Nanoelectromechanical microwave switch based on graphene. In Proceedings of the 2013 14th International Conference on Ultimate Integration on Silicon (ULIS), Coventry, UK, 19-21 March 2013; pp. 189-192. [CrossRef]

25. Litun, Y.; Litun, V.; Kononenko, O.; Chichkov, M.; Borisenko, D. Technological Features of Graphene-based RF NEMS Capacitive Switches on a Semi-insulating Substrate. In Proceedings of the 2019 PhotonIcs \& Electromagnetics Research Symposium-Spring (PIERS-Spring), Rome, Italy, 17-20 June 2019; pp. 3666-3672. [CrossRef]

26. Fan, C.; Wu, B.; Hu, Y.; Zhao, Y.; Su, T. Millimeter-Wave Pattern Reconfigurable Vivaldi Antenna Using Tunable Resistor Based on Graphene. IEEE Trans. Antennas Propag. 2019, 68, 4939-4943. [CrossRef]

27. Wu, B.; Zhang, Y.; Zu, H.; Fan, C.; Lu, W. Tunable Grounded Coplanar Waveguide Attenuator Based on Graphene Nanoplates. IEEE Microw. Wirel. Components Lett. 2019, 29, 330-332. [CrossRef]

28. Zhang, A.-Q.; Liu, Z.-G.; Wei-Bing, L.; Chen, H. Graphene-Based Dynamically Tunable Attenuator on a Coplanar Waveguide or a Slotline. IEEE Trans. Microw. Theory Tech. 2018, 67, 70-77. [CrossRef]

29. Zhang, A.-Q.; Liu, Z.-G.; Lu, W.-B.; Chen, H. Dynamically Tunable Attenuator on a Graphene-Based Microstrip Line. IEEE Trans. Microw. Theory Tech. 2018, 67, 746-753. [CrossRef]

30. Island, J.O.; Kissin, P.; Schalch, J.; Cui, X.; Haque, S.R.U.; Potts, A.; Taniguchi, T.; Watanabe, K.; Averitt, R.D.; Young, A. On-chip terahertz modulation and emission with integrated graphene junctions. Appl. Phys. Lett. 2020, 116, 161104. [CrossRef]

31. SSun, Z.; Martinez, A.; Wang, F. Optical modulators with 2D layered materials. Nat. Photon. 2016, 10, 227-238. [CrossRef]

32. Pengelly, R.S.; Wood, S.M.; Milligan, J.W.; Sheppard, S.T.; Pribble, W.L. A Review of GaN on SiC High Electron-Mobility Power Transistors and MMICs. IEEE Trans. Microw. Theory Tech. 2012, 60, 1764-1783. [CrossRef]

33. Wang, M.; Yang, E.-H. Terahertz Applications of Graphene. Handbook of Graphene; Harun, S.H., Ed.; Scrivener Publishing LLC: Beverly, MA, USA, 2019; Volume 8, pp. 341-358.

34. Goniszewski, S.; Adabi, M.; Shaforost, O.; Hanham, S.; Hao, L.; Klein, N. Correlation of p-doping in CVD Graphene with Substrate Surface Charges. Sci. Rep. 2016, 6, 22858. [CrossRef] [PubMed]

35. Ciuk, T.; Pasternak, I.; Krajewska, A.; Sobieski, J.; Caban, P.; Szmidt, J.; Strupinski, W. Properties of Chemical Vapor Deposition Graphene Transferred by High-Speed Electrochemical Delamination. J. Phys. Chem. C 2013, 117, 20833-20837. [CrossRef]

36. Dub, M.; Sai, P.; Przewłoka, A.; Krajewska, A.; Sakowicz, M.; Prystawko, P.; Kacperski, J.; Pasternak, I.; Cywiński, G.; But, D.; et al Graphene as a Schottky Barrier Contact to AlGaN/GaN Heterostructures. Materials 2020, 13, 4140. [CrossRef] [PubMed]

37. Bogdan, G.; Godziszewski, K.; Yashchyshyn, Y.; Kim, C.H.; Hyun, S.-B. Time-Modulated Antenna Array for Real-Time Adaptation in Wideband Wireless Systems—Part I: Design and Characterization. IEEE Trans. Antennas Propag. 2019, 68, 6964-6972. [CrossRef] 